\title{
Immunization with ovarian autoantigens leads to reduced fertility in mice following follicular dysfunction
}

\author{
Purvi V Mande ${ }^{1}$, Susan Thomas ${ }^{2}$, Shagufta Khan ${ }^{1}$, Sudhir Jadhav ${ }^{1}$ and Vrinda V Khole ${ }^{1}$ \\ ${ }^{1}$ Department of Gamete Immunobiology and ${ }^{2}$ Biomedical Informatics Center of ICMR, National Institute for Research \\ in Reproductive Health (Indian Council of Medical Research), Jehangir Merwanji Street, Parel, Mumbai 400012, India \\ Correspondence should be addressed to VV Khole; Email: kholev@nirrh.res.in
}

\begin{abstract}
Immunoproteomics using sera of women with ovarian autoimmune diseases such as primary ovarian insufficiency and IVF embryo transfer recruits led to identification of three proteins namely alpha actinin 4 ( $\alpha$-ACTN4), heat-shock 70 protein 5 (HSPA5), and actin beta (ACTB). This study deals with the establishment of a peptide ELISA for screening sera of antiovarian antibody (AOA)-positive patients and further delves into understanding the role of these three proteins in ovarian autoimmunity in a mouse model. Using in silico approach, antigenic peptides of these proteins were identified and used for peptide ELISA. ELISA results indicated that AOA-positive sera showed reactivity with only specific peptides. The functional significance of the dominant peptides was studied by active immunization of female mice with these peptides. All immunized mice generated high antibody titers and profound effect on ovaries with few primordial (2.4 $\pm 0.1,2.4 \pm 0.2$, and $2 \pm 0.1$ ), primary $(2.4 \pm 0.5,1.7 \pm 0.3$, and $2.4 \pm 0.3)$, preantral $(2.3 \pm 0.5,3.4 \pm 0.3$, and $2.9 \pm 0.3)$, antral $(0.9 \pm 0.2,1.6 \pm 0.8$, and $2.3 \pm 0.6)$ follicles, and corpora lutea $(2.8 \pm 0.8,2.9 \pm 1.7$, and $4.6 \pm 2.3)$, and increased number of atretic follicles $(5.5 \pm 0.4,4.9 \pm 1.8$, and $7.5 \pm 1.0)$ in ACTN4-, HSPA5-, and ACTB-immunized mice compared with control animals (3.0 \pm 0.2 , $3.5 \pm 0.6,3 \pm 0.1,3.6 \pm 0.2,4.7 \pm 0.3$, and $1.5 \pm 0.3$ ) respectively. These mice when mated with fertile male mice showed an overall $25-43 \%$ reduction in fertility compared with controls. The data clearly suggest that the dominant antigenic epitopes of the three proteins play critical role in fertility and could possibly be the key autoimmune targets. These epitopes could be used to develop a more specific and sensitive diagnostic test for women with ovarian autoimmune diseases and to design therapy for disease management for reinstatement of ovarian function.

Reproduction (2012) 143 309-323
\end{abstract}

\section{Introduction}

The prospects for significant improvement in treatment of premature ovarian failure (POF) or primary ovarian insufficiency (POI) reside in early diagnosis of the disease. Although majority of POI and IVF-embryo transfer (IVF-ET) failure cases have no clear etiology, newer lines of evidence indicate that autoimmunity of the ovary significantly contributes to ovarian dysfunction. The diagnosis of autoimmune ovarian failure is based on the detection of circulating autoantibodies to ovarian antigens, but specific ovarian antigens as well as their relevance to autoimmune disease development have not been demonstrated. Antibodies to multiple ovarian antigens have been proposed as markers of ovarian autoimmunity, which include steroidogenic enzymes, zona pellucida, and cytoskeletal proteins (Damewood et al. 1986, Winqvist et al. 1993, Gobert et al. 2001, Luborsky 2002, Forges et al. 2004, Sundblad et al. 2006, Edassery et al. 2010). A recent study (Otsuka et al. 2011) shows that multiple antigens play a role in murine autoimmune oophoritis model, but the exact nature of these antigens has not been elucidated. Autoimmune POI is characterized by inflammatory infiltration of developing follicles or presence of autoantibodies and a decrease in the pool of developing follicles (Hoek et al. 1997). Mostly, the diagnosis has relied on the detection of antiovarian antibodies (AOAs). But due to lack of availability of specific and sensitive assay systems for the detection of these antibodies, the disease remains undetected till it reaches advanced stages. It is, therefore, important to identify the ovarian autoantigens playing significant role in ovarian autoimmune pathologies. We demonstrated the presence of multiple antigenic targets in the range of $30-220 \mathrm{kDa}$, of which 45, 80, 90, 97, and $120 \mathrm{kDa}$ proteins were found to be predominantly targeted by the sera of infertile women. Four of these immunodominant ovarian autoantigens were identified and characterized extensively in our previous studies using sera of women with POI and women recruited under IVF-ET program (Pires \& Khole 2009, Mande et al. 2011). The three proteins, i.e. alpha actinin $4(\alpha$-ACTN4), heat-shock 70 protein 5 (HSPA5), and actin beta (ACTB), have been 
shown to be autoimmune targets in the pathophysiology of other autoimmune diseases like systemic lupus erythematosus, rheumatoid arthritis, multiple sclerosis, Sjogren's syndrome, autoimmune inner ear disease, neuropsychiatric systemic lupus erythematosus, and autoimmune hepatitis type I (McClure \& Shearer 1988, Boulassel et al. 2001, Purcell et al. 2003, Bodman Smith et al. 2004, Gueguen et al. 2006, Kimura et al. 2008). However, we were the first to report the presence of antibodies to these proteins in infertile women with autoimmune etiology. Furthermore, an ELISA using recombinant proteins ( $\mathrm{Rp}$ ) was proposed as the primary screening method for the serodiagnosis of women with POI and IVF-ET failures (Mande et al. 2011).

Global epitope or antigen profiling using serum antibodies as analytes has been extensively investigated for diagnostic purposes. This high-throughput arraybased serological detection method is an upcoming screening tool being applied for the assessment of autoantibody response against specific proteins like MUC16 (CA125; Mederois et al. 2009). Native or recombinant antigens are powerful reagents for serodiagnosis due to the presence of a large spectrum of epitopes that cover variations in the individual responses among patients. However, it sometimes compromises the specificity of the system due to several cross-reactive epitopes. Synthetic peptides mimicking relevant B-cell and/or T-cell epitopes are potentially ideal tools for dissecting the antigenicities of the native antigens, making it possible to measure antibodies directed against very specific antigenic determinants (Elkon 1992). Additionally, synthetic peptides in contrast to biological products are easily standardized and can be readily produced in large amounts. Consequently, an increasing number of diagnostic assays based on synthetic peptides representing diagnostically relevant epitopes are being developed and some are already commercially available (Hardy et al. 2004). Prediction of antigenic epitopes relies mainly on the physicochemical properties of amino acids like hydrophilicity, solvent accessibility, and flexibility and also on secondary structure of the protein (Hopp \& Woods 1981, Parker et al. 1986, Kolaskar \& Tongaonkar 1990). There exist very few reports on the autoantigens involved in ovarian autoimmunity and there are no reports citing the three immunodominant ovarian autoantigens namely $\alpha$-ACTN4, ACTB, and HSPA5 or their antigenic epitopes. This study describes the identification of the dominant antigenic regions of the three autoantigens, using sera of women with POI and women recruited under IVF-ET program in an ELISA-based assay system.

Besides their role as autoantigens, all the three antigenic proteins have been reported to play an important role in fertilization and early developmental events in different species. Actin has been shown to play an important role in oogenesis, fertilization, and a wide range of important events during early embryogenesis
(Velarde et al. 2007). Similarly, $\boldsymbol{\alpha}$-ACTN4 has been shown to be required in oocyte microvilli development in fetal baboon oocyte (Zachos et al. 2008). HSPA5 (GRP78) has been reported to be essential for embryonic cell growth and pluripotent cell survival, and it is observed that embryos devoid of HSPA5 exhibit a substantial increase in apoptosis of the inner cell mass and $G R P 78^{-1-}$ embryos led to peri-implantation lethality (Luo et al. 2006). The probable role of all these three proteins as ovarian autoantigens in women with POI and IVF-ET failures was reported for the first time by our group (Mande et al. 2011). In the same study, we also showed localization of these three antigens on oocytes and during early embryonic stages in the ontogeny studies indicating a requirement of these proteins in fertilization and follicular maturation events. Different animal models exist for autoimmune ovarian failure disease, which underline important information about the possible mechanism of autoimmune ovarian disease development and the role of ovarian antigens in disease progression. It has been proposed that ovarian failure in autoimmune destruction of the ovaries can be induced in animals by different approaches such as immunization with crude ovarian extract or specific ovarian antigen like zona pellucida or peptides, neonatal thymectomy or by transfer of normal T-cells into syngeneic athymic nude mice (Hoek et al. 1997). Immunization with crude ZP antigens led to production of antibodies and depletion of follicles (Skinner et al. 1984). The autoantigenic targets identified in our previous study (Mande et al. 2011) have been shown to be localized in the functionally important components of the ovary namely oocyte, theca, granulosa, and corpus luteum (CL). Follicular growth is exquisitely regulated by intraovarian oocyte-granulosa-theca cell interactions. Therefore, in this study, we have investigated whether active immunization of female mice with dominant peptides of these autoantigenic proteins induces a pathological condition in the animals more closely mimicking an autoimmune ovarian disease in women. These data would enable us to establish the functional relevance of these molecules in folliculogenesis and fertility in a mouse model.

\section{Results \\ Predicted antigenic peptides}

Peptides that were predicted for antigenicity were synthesized, the details of which are mentioned in Table 1. The start and the end positions refer to the residue number of the first and the last amino acid of the peptide, respectively, as documented in the corresponding SwissProt entries of the proteins. The flexibility of the conformations and the presence of secondary structures such as beta-turns are known to be crucial determinants of antigenicity (Alix 1999). Among the secondary structures, loops offer the greatest extent of 
Table 1 Sequences of synthetic peptides and their location in proteins.

\begin{tabular}{|c|c|c|c|c|}
\hline Peptide no. & Protein & $\begin{array}{l}\text { Location of } \\
\text { amino acid residues } \\
\text { in protein }\end{array}$ & Amino acid sequence & Purity (\%) \\
\hline 1 & Alpha actinin 4 & 4-18 & YHAANQSYQYGPS & 99.04 \\
\hline 2 & Alpha actinin 4 & 69-83 & TQIENIDEDFRDGLK & 98.15 \\
\hline 3 & Alpha actinin 4 & $176-186$ & KTAPYKNVNVQN & 99.40 \\
\hline 4 & Alpha actinin 4 & $206-219$ & RPELIEYDKIRKDD & 98.55 \\
\hline 5 & Alpha actinin 4 & 94-105 & ERLPKPERGKMR & 98.98 \\
\hline 6 & Alpha actinin 4 & $553-562$ & DMFIVHTIEE & 98.29 \\
\hline 7 & Alpha actinin 4 & $864-876$ & EELRRELPPDQAE & 98.57 \\
\hline 8 & Alpha actinin 4 & $121-130$ & SKGVKLVSIG & 98.23 \\
\hline 9 & Alpha actinin 4 & $613-627$ & KLSGSNPYTVTPQI & 98.06 \\
\hline 10 & Alpha actinin 4 & $154-168$ & AIQDISVEETSAKEG & 98.67 \\
\hline 1 & Actin beta & $2-15$ & DDDIAALVVDNGSG & 98.23 \\
\hline 2 & Actin beta & $38-50$ & PRHQGVMVGMGQK & 98.07 \\
\hline 3 & Actin beta & $322-336$ & PSTMKIKIIAPPERK & 99.95 \\
\hline 4 & Actin beta & $354-366$ & QMWISKQEYDESG & 98.75 \\
\hline 5 & Actin beta & $91-103$ & YNELRVAPEEHPV & 98.07 \\
\hline 6 & Actin beta & $235-247$ & SLEKSYELPDGQV & 98.06 \\
\hline 7 & Actin beta & $51-63$ & DSYVGDEAQSKRG & 98.36 \\
\hline 8 & Actin beta & $106-118$ & TEAPLNPKANREK & 98.73 \\
\hline 9 & Actin beta & 195-205 & ERGYSFTTTAE & 98.81 \\
\hline 10 & Actin beta & $167-179$ & EGYALPHAILRLD & 98.44 \\
\hline 1 & Heat-shock 70 protein 5 & $26-40$ & EDVGTVVGIDLGTTY & 98 \\
\hline 2 & Heat-shock 70 protein 5 & $211-220$ & GLDKREGEKN & 99.75 \\
\hline 3 & Heat-shock 70 protein 5 & $345-358$ & KVLEDSDLKKSDID & 98.19 \\
\hline 4 & Heat-shock 70 protein 5 & $381-392$ & NGKEPSRGINPD & 98 \\
\hline 5 & Heat-shock 70 protein 5 & $274-284$ & KTGKDVRKDNR & 98.01 \\
\hline 6 & Heat-shock 70 protein 5 & $547-557$ & EKFAEEDKKLK & 98.12 \\
\hline 7 & Heat-shock 70 protein 5 & 487-495 & GIPPAPRGV & 98.69 \\
\hline
\end{tabular}

conformational flexibility to the protein. The 3D structures of the predicted antigenic peptides reveal that majority of them adopt the expected beta-turns and loop conformations.

\section{Patients' sera react with immunodominant peptides}

Ten predicted antigenic peptides each of $\alpha$-ACTN4 protein and ACTB protein and seven predicted peptides of HSPA5 protein were used to screen the patients' sera positive for these three proteins (identified in the previous study using 1D western blot and Rp ELISA; Mande et al. 2011). Peptide ELISA was used to determine the most antigenic peptides among these three groups of proteins. The number of patients' (Np) and control (Nc) sera screened with each peptide of every protein was as follows: $\alpha$-ACTN4, $\mathrm{Np}=43, \mathrm{Nc}=34$; HSPA5, $\mathrm{Np}=64$, $\mathrm{Nc}=35$; and $\mathrm{ACTB}, \mathrm{Np}=30, \mathrm{Nc}=31$. The absorbance values plotted on a scatter plot are represented in Fig. 1. Using a cutoff value (mean +2 s.D.) based on control samples, peptides 1 (YHAANQSYQYGPS), 2 (TQIENIDEDFRDGLK), 5 (ERLPKPERGKMR), 7 (EELRRELPPDQAE), 8 (SKGVKLVSIG), 9 (KLSGSNPYTVTPQI), and 10 (AIQDISVEETSAKEG) of $\boldsymbol{\alpha}$-ACTN4; peptides 3 (KVLEDSDLKKSDID), 5 (KTGKDVRKDNR), 6 (EKFAEEDKKLK), and 7 (GIPPAPRGV) of HSPA5; and peptides 2 (PRHQGVMVGMGQK), 3 (PSTMKIKIIAPPERK), 5 (YNELRVAPEEHPV), 8 (TEAPLNPKANREK), and 10 (EGYAL-
PHAILRLD) of ACTB were found to be statistically significant with $P<0.001$ (depicted as pink filled triangles on the scatter plot). There was no crossreactivity observed among the sera samples of the three proteins using an unrelated peptide (URP as shown by blue filled triangles). The sensitivity, specificity, and diagnostic accuracy of the antipeptide antibodies of $\alpha$-ACTN4, HSPA5, and ACTB peptides are depicted in Table 2, indicating that peptides 1,2 , and 5 of $\alpha$-ACTN4; peptides 3, 5, and 6 of HSPA5; and peptides 5, 8, and 10 of ACTB were the most immunodominant epitopes (indicated by blue font).

\section{Active immunization-induced autoantibodies in mice}

Based on the results and statistical analysis of the peptide ELISA using patient sera, the peptides showing highest sensitivity and specificity in each protein group $(n=3)$ were pooled as shown in Table 3 for immunization in mice. The antibody levels in serum samples of immunized mice as well as control mice against the pooled peptides were assayed at different time intervals by ELISA. Specific antibodies were detected in the mouse serum in each of the groups $(1,2$, and 3$)$ against the respective peptides by the second week (2W) after the first immunization. The antibody levels (indicated as purple filled triangles in Fig. 2) elevated gradually by the fourth week $(4 \mathrm{~W})$ and peaked at the sixth week $(6 \mathrm{~W})$. 

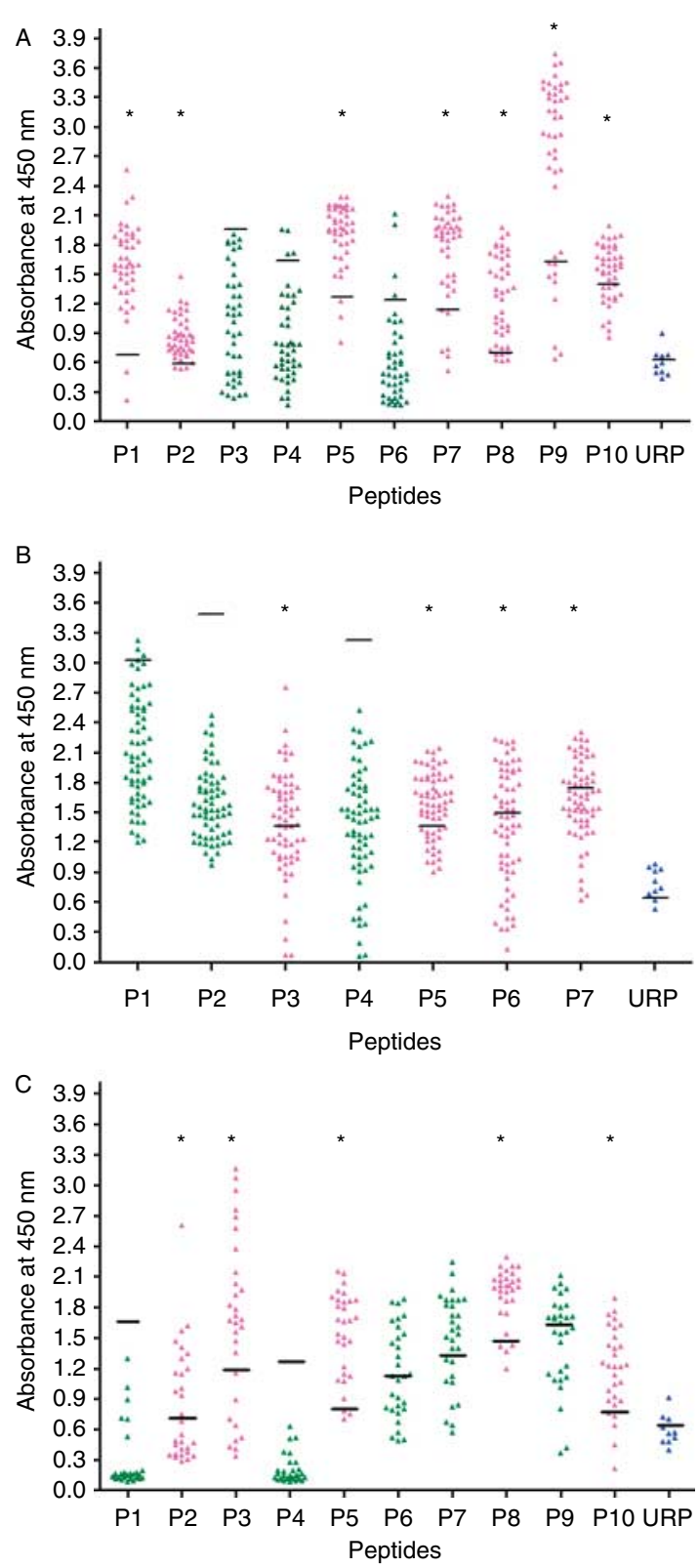

Figure 1 The figure depicts the reactivity of (A) $\alpha$-ACTN4, (B) HSPA5, and (C) ACTB-positive sera from infertile women to ten peptides of $\alpha$-ACTN4, seven peptides of HSPA5, and ten peptides of ACTB, respectively, using peptide ELISA. The horizontal line represents the cutoff value determined by mean +2 s.D. of control absorbance. All values above the line indicate a positive reactivity of the patient samples to a particular peptide. Peptides P1, P2, P5, P7, P8, P9, and P10 of $\alpha$-ACTN4; peptides P3, P5, P6, and P7 of HSPA5; and peptides P2, P3, P5, P8, and P10 of ACTB showed strong immunoreactivity to the respective patients' sera with maximum values falling above the cutoff limit. An unrelated peptide (URP) shows absorbance values similar to that of control reading. *Statistically significant differences in mean absorbance values against the peptide $(P<0.05$ from MannWhitney $U$ test). Statistically significant peptides are depicted as pink filled triangles; those which are not significant are represented by green filled triangles, and the URP as blue filled triangles in the scatter plot. Immunodominant epitopes of $\boldsymbol{\alpha}$-ACTN4, HSPA5, and ACTB proteins were predicted by algorithms namely Kolaskar-Tongaonkar, Bepipred, and DISCOTOPE.
The PBS group (depicted as green filled triangles) served as control and provided the background level (Fig. 2). No significant antibody levels were detected using sera from mice immunized with $\mathrm{KLH}$-conjugated peptides against $\mathrm{KLH}$ peptide alone or using sera from $\mathrm{KLH}$ immunized animals (KLH control group) against the $\mathrm{KLH}$-conjugated peptides by ELISA, indicating that the response is specific to the peptide and not to KLH (data not shown). We observed significant (unpaired t-test, $P<0.0001)$ reactivity of these sera against the dominant epitopes.

\section{Specificity of antipeptide antibodies to target proteins}

The specificity of antipeptide sera against the native proteins of the ovary was evaluated by western blot analysis (Fig. 3). Recombinant $\alpha$-ACTN4, HSPA5, and ACTB proteins and mouse whole ovarian lysate were used to identify the antipeptide antibody specificity to the respective proteins. Results indicated that the pooled antisera of each immunized group at 6 weeks (when sera antibody titer reached its maximum as detected by ELISA) recognized the native proteins in ovarian lysate (Mo), i.e. $\alpha$-ACTN4 at $105 \mathrm{kDa}$, HSPA5 at $72 \mathrm{kDa}$, ACTB at $41 \mathrm{kDa}$, and the full-length GST-tagged Rp $\alpha$-ACTN4 at $131 \mathrm{kDa}, \mathrm{HSPA} 5$ at $98 \mathrm{kDa}$, and ACTB at $67 \mathrm{kDa}$ (panels A, B, and C, lane 4). These specific bands were not observed when total ovarian lysate and $\mathrm{Rp}$ were probed with PBS alone (panels A, B, and C, lane 1), postimmune sera from control animals (panels $A, B$, and $C$, lane 2) and preimmune sera of immunized animals (panels A, B, and C, lane 3).

\section{Antipeptide antibodies alter ovarian cytoarchitecture}

Histological sections of the ovaries (five sections per ovary, $n=4$ ovaries per group) from the peptideimmunized and PBS control animals were examined for evidence of ovarian pathology 6 weeks after immunization (Fig. 4A). Ovaries from control group contained healthy primary, preantral (PAF), and antral follicles (AF); corpora lutea (CL); and cumulus-oocyte complexes (COCs) with very few atretic follicles (panel a, 1-4). However, ovaries from peptide-immunized mice from all three groups showed significant changes in the cytoarchitecture with extensive depletion of healthy ovarian follicles. Immunization with peptides caused substantial depletion of follicles at each developmental stage, with mature follicles showing greatest depletion. They lacked healthy oocytes (panels b, c, and d, 2-3 indicated by black arrows) and contained few healthy primordial follicles, primary follicles, PAFs, and AFs (panels b1, c1, and d1) and fewer healthy CL (panels b4, c4, and $d 4$, indicated by yellow arrowhead) with irregular theca and granulosa cell layers (panels b, c, and $d, 1-3$ indicated by green and red arrowheads 
Table 2 Diagnostic performance of the synthetic peptides in the immunodiagnosis of autoimmune premature ovarian failure and IVF-embryo transfer recruits by peptide ELISA.

\begin{tabular}{|c|c|c|c|c|c|c|}
\hline S. no. & Protein & Peptide no. & Peptide sequence & Sensitivity (\%) & Specificity (\%) & $\begin{array}{c}\text { Diagnostic } \\
\text { accuracy }(\%)\end{array}$ \\
\hline 1 & $\alpha$-ACTN4 & 1 & YHAANQSYQYGPS & 95.34 & 93.75 & 94.6 \\
\hline 2 & $\alpha$-ACTN4 & 2 & TQIENIDEDFRDGLK & 93.02 & 78.12 & 86.6 \\
\hline 3 & $\alpha$-ACTN4 & 5 & ERLPKPERGKMR & 93.02 & 84.37 & 89.3 \\
\hline 4 & $\alpha$-ACTN4 & 7 & EELRRELPPDQAE & 88.37 & 90.62 & 89.3 \\
\hline 5 & $\alpha$-ACTN4 & 8 & SKGVKLVSIG & 79.06 & 71.87 & 76 \\
\hline 6 & $\alpha$-ACTN4 & 9 & KLSGSNPYTVTPQI & 79.06 & 96.87 & 86.6 \\
\hline 7 & $\alpha$-ACTN4 & 10 & AIQDISVEETSAKEG & 69.76 & 72.09 & 81.3 \\
\hline 1 & HSPA5 & 3 & KVLEDSDLKKSDID & 56.25 & 82.85 & 65.6 \\
\hline 2 & HSPA5 & 5 & KTGKDVRKDNR & 67.18 & 93.54 & 72.7 \\
\hline 3 & HSPA5 & 6 & EKFAEEDKKLK & 40.62 & 97.05 & 59.5 \\
\hline 4 & HSPA5 & 7 & GIPPAPRGV & 20.31 & 100 & 47.4 \\
\hline 1 & ACTB & 2 & PRHQGVMVGMGQK & 36.6 & 96.77 & 67.2 \\
\hline 2 & АСТВ & 3 & PSTMKIKIIAPPERK & 50 & 100 & 75.4 \\
\hline 3 & ACTB & 5 & YNELRVAPEEHPV & 80 & 96.77 & 88.5 \\
\hline 4 & ACTB & 8 & TEAPLNPKANREK & 83.3 & 93.54 & 88.5 \\
\hline 5 & ACTB & 10 & EGYALPHAILRLD & 60 & 93.54 & 77 \\
\hline
\end{tabular}

respectively). A thin granulosa layer in growing AFs was observed in immunized mice compared with thick layer of granulosa in control mice (panels b3, c3, and d3 pointed by red arrowhead). We also observed that the structure of COCs (depicted as orange arrowhead) in immunized mice was less condensed and less intact than that from control mice. To quantify the effect of antipeptide antibodies on ovarian follicle development, the numbers of primordial follicles, primary follicles, $\mathrm{PAF}, \mathrm{AF}$, atretic follicles, and $\mathrm{CL}$ were quantified and are represented in Fig. 4B. There was a significant decrease in the number of primordial $(2.45 \pm 0.17,2.4 \pm 0.2$, and $2 \pm 0.11$ per $\left.\mathrm{mm}^{2}\right)$, primary $(2.45 \pm 0.5,1.7 \pm 0.35$, and $2.4 \pm 0.3$ per $\left.\mathrm{mm}^{2}\right)$, and antral $(0.9 \pm 0.25,1.65 \pm 0.85$, and $2.35 \pm 0.6$ per $\mathrm{mm}^{2}$ ) follicles in group 1 (depicted as orange bar), group 2 (red bar), and group 3 (blue bar), respectively, compared with control group $(3.05 \pm 0.23$, $3.5 \pm 0.6$, and $3.6 \pm 0.24$ per $\mathrm{mm}^{2}$, green bar). There was a decline in the mean number of PAFs ( $g r 1=2.3 \pm 0.5$, gr2 $=3.4 \pm 0.35$, and gr $3=2.95 \pm 0.3$ per $\mathrm{mm}^{2}$ ) and $\mathrm{CL}$ (gr1 $=2.8 \pm 0.85$, gr2 $=2.9 \pm 1.7$, and gr $3=4.6 \pm 2.3$ per $\left.\mathrm{mm}^{2}\right)$ compared with the control group $(3 \pm 0.15$ and $4.7 \pm 0.35$ per $\mathrm{mm}^{2}$ ), although this did not reach statistical significance. Number of atretic follicles was significantly higher in the immunized groups (gr1 $=5.5 \pm 0.45$, gr2 $=4.95 \pm 1.8$, and gr3 $=7.5 \pm 1.05$ per $\left.\mathrm{mm}^{2}\right)$ compared with the control group $(1.5 \pm 0.35$ per $\mathrm{mm}^{2}$ ).

\section{Antipeptide antisera recognize autoantigens in ovary}

To further evaluate the effects of antipeptide antibodies on specific cell types, immunohistochemistry was performed on normal mouse ovarian sections as depicted in Fig. 5a. Reactivity of anti- $\alpha$-ACTN4 (Fig. 5a (B)), anti-HSPA5 (Fig. 5a (C)), and anti-ACTB (Fig. 5 (D)) antibodies showed positive staining in oocyte (panels 1 and 2 depicted as black arrow), theca (panel 2 depicted as green arrowhead), granulosa (panel 2 depicted as red arrow), and $\mathrm{CL}$ (panel 3 depicted by yellow arrowhead). The antisera from control animals (Fig. 5a (A), panels 1-3) and PBS alone (data not shown) did not show any reactivity to any of the cell types.

In the direct immunofluorescence as depicted in Fig. 5b, ovarian sections of mice immunized with $\alpha$-ACTN4 (Fig. 5b (B)), HSPA5 (Fig. 5b (C)), and ACTB (Fig. 5b (D)) peptides showed positive staining in oocyte (panel 1 depicted as white arrow), theca (panel 1 depicted as orange arrowhead), granulosa (panel 1 depicted as red arrow), and $\mathrm{CL}$ (panel 2 depicted by yellow arrowhead). The ovaries from control animals (Fig. 5b (A), panels 1-2) did not show any reactivity to any of the cell types.

\section{Autoantibodies affect mouse fertility}

Two weeks after the final immunization, immunized female mice were mated continuously with proven

Table 3 Treatment groups designated by immunization modalities.

\begin{tabular}{lclll}
\hline Treatment groups & $\begin{array}{c}\text { No. of animals } \\
\text { immunized }\end{array}$ & Immunogen (prime) & Immunogen (boost) & $\begin{array}{c}\text { No. of animals } \\
\text { for mating }\end{array}$ \\
\hline Control & 14 & PBS/KLH & PBS/KLH & 10 \\
Group 1 ( $\boldsymbol{\alpha}$-ACTN4) & 14 & Peptides 1 $+2+5$ & Peptide $1+2+5$ & 10 \\
Group 2 (HSPA5) & 14 & Peptides 3+5 +6 & Peptide 3+5 +6 & 10 \\
Group 3 (ACTB) & 14 & Peptides 5+8+10 & Peptide 5+8+10 & 10 \\
\hline
\end{tabular}



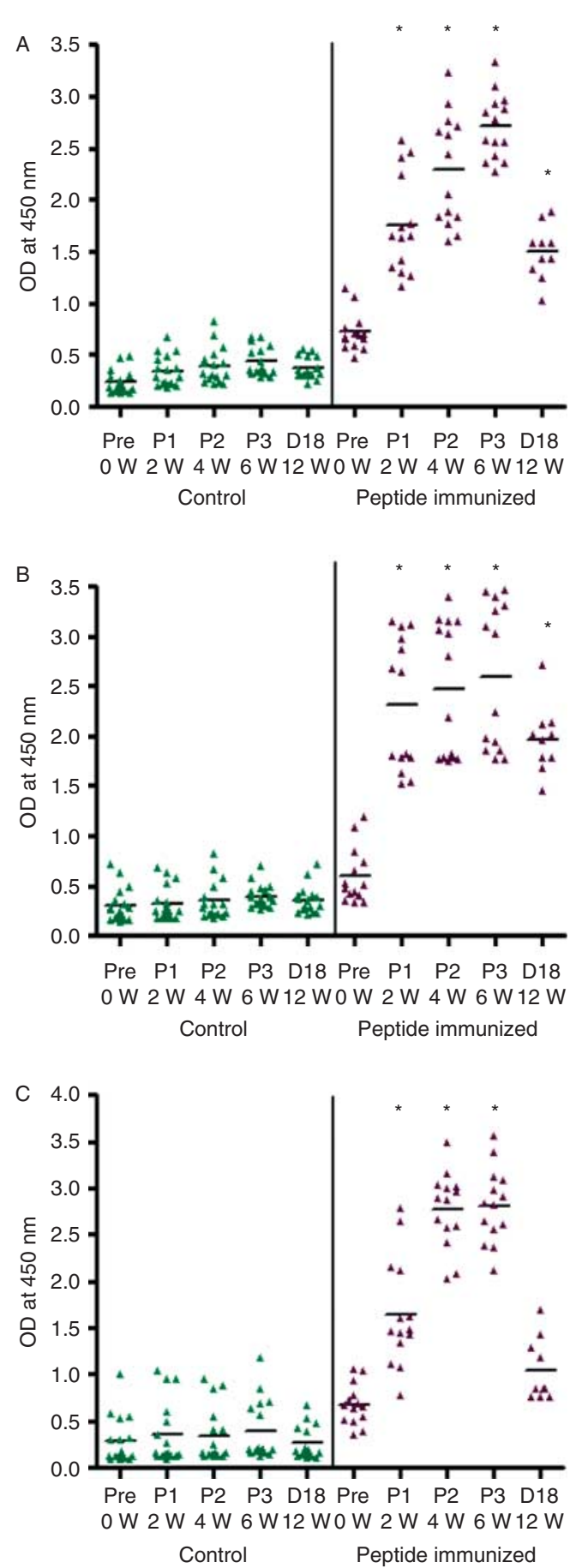

Figure 2 Immune response in Balb/c female mice injected with $\mathrm{KLH}$ conjugated antigenic peptides of (A) group 1 ( $\alpha$-ACTN4 peptides), (B) group 2 (HSPA5 peptides), (C) group 3 (ACTB peptides), and control mice immunized with PBS or KLH alone. Antibody titers in sera of control $(n=14)$ and immunized mice $(n=14)$ were detected by ELISA at different time intervals (2W, 4W, 6W, and D18 of pregnancy). Pre, preimmune sera; $\mathrm{P} 1$, postimmune sera after 2 weeks; P2, postimmune sera after 4 weeks; P3, postimmune sera after 6 weeks; D18, sera at pregnancy day 18 ( 12 weeks); W, weeks. Antibody levels in control and peptideimmunized mice are depicted by green and purple filled triangles respectively. Horizontal line depicts the mean OD values. Data are presented as absorbance at $450 \mathrm{~nm},{ }^{*} P<0.0001$ by unpaired $t$-test. fertile, sexually mature male mice to determine the effect of immunization on mouse fertility. The mean viable fetii among the immunized pregnant female mice in each immunized group were counted and compared with the control groups. Also, the number of implantation sites in the uterus and the number of CLs visible on ovaries were counted. In control group, all the females became pregnant. Although a delay in pregnancy was observed in $30 \%$ of mice from group 1 ( $29.33 \pm 4.5$ days from the day of detection of vaginal plug (VP)) and group 3 $(36.33 \pm 7.23$ days after VP), while $20 \%$ of mice did not become pregnant in groups 2 and 3 even after 60 days of detection of VP. Pregnancy failure as evidenced by decrease in the number of implantations was found in all three immunized groups. There was a significant increase in the percentage of preimplantation loss (depicted as green bars) in group 1 (gr1, 24\%), group 2 (gr2, 44\%), and group 3 (gr3, 36.4\%) when compared with the control group (Cntrl, 5.5\%, $P<0.05$ ). The percentage of postimplantation loss was increased (depicted as blue bars), but it did not reach statistical significance in group 1 (gr1, 8.0\%), group 2 (gr2, 9.7\%), and group 3 (gr3, 11.5\%) compared with controls (Cntrl, 0.0) (Fig. 6A). The number of fetii per pregnant female was lower in all three immunized groups. Consequently, as shown in Fig. 6B, the fertility index of the mice immunized with group 1 (5.8 \pm 0.757 , checkered bar), group $2(4.4 \pm 0.933$, horizontal line bar), and group 3 (5.3 \pm 1.00 , vertical line bar) peptides was low compared with control animals $(7.7 \pm 0.423$, unfilled bar). There was an overall 25,43 , and $32 \%$ reduction in fertility in groups 1, 2, and 3, respectively, compared with control group. A representative picture of the viable embryos (panel 1) and resorbed embryos (panel 2) in the uterus of control and immunized mice is shown in Fig. 6C. Additionally, vaginal smears were taken daily from immunized as well as control (nonimmunized) mice. It was observed that the immunized mice had significantly longer diestrus (group 1, $5.78 \pm 0.47$ days; group 2, $6.42 \pm 0.45$ days; and group $3,4.0 \pm 0.2$ days) compared with the control mice ( $2.5 \pm 0.13$ days).

\section{Discussion}

Autoimmunity seems to be an important immunological factor implicated in the etiology of infertility especially in cases like POI and IVF-ET failures (Coulam et al. 1986). Despite several investigations on ovarian autoimmunity, the exact nature of ovarian autoantigens that may serve as biomarkers for diagnosis of ovarian autoimmune diseases specifically POI and IVF-ET failures has not been successfully established. Earlier studies from our group have clearly indicated the presence of autoantibodies against four dominant ovarian antigens namely heat-shock protein $90 \beta$ (HSP90 $\beta$; Pires \& Khole 2009), $\alpha$-ACTN4, HSPA5, and ACTB (Mande et al. 2011) in the sera of women with POI and IVF-ET failures. 
Furthermore, an ELISA using Rp was proposed as the primary screening method for the serodiagnosis of women with POI and IVF-ET failures (Mande et al. 2011). However, the specificity of the assay system is
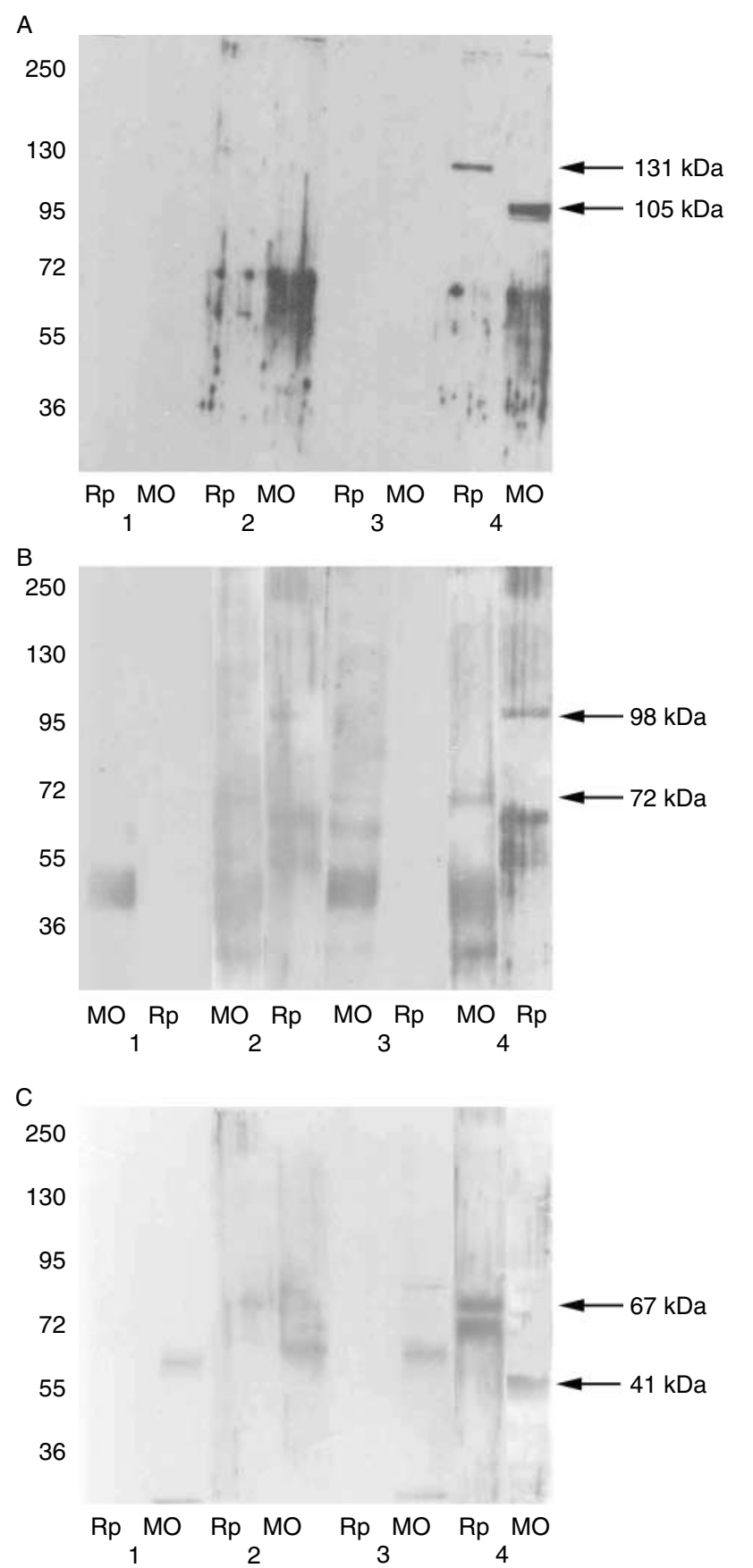

Figure 3 Western blot analysis of recombinant proteins (Rp), alpha actinin $4(\mathrm{~A})$, heat-shock 70 protein $5(\mathrm{~B})$, and actin beta (C) and mouse ovarian lysate (Mo) probed with pooled mice sera from group $1(\alpha-$ ACTN4 peptides), group 2 (HSPA5 peptides), group 3 (ACTB peptides), and control group (PBS alone). Rp and Mo probed with lane 1: PBS alone; lane 2: pooled sera from control mice; lane 3: pooled preimmune sera from immunized animals; and lane 4: pooled postimmune sera from immunised animals taken at 6 weeks. Arrows indicate the respective molecular sizes. compromised due to several cross-reactive epitopes when native or $\mathrm{Rp}$ are employed for serodiagnosis. It has been reported that synthetic peptides mimicking relevant B-cell and/or T-cell epitopes are potentially ideal tools for dissecting the antigenicities of the native antigens, making it possible to measure antibodies directed against very specific antigenic determinants (Elkon 1992). Therefore, in this study, we carried out experiments to determine whether the reactivity was focused selectively to particular regions of the molecules or the whole molecule per se. Toward this, we dissected out the antigenic regions of the three identified autoimmune targets using antigenicity prediction algorithms and peptide ELISA was performed with the AOApositive sera from patients with POI and IVF-ET failures. The data clearly indicated that the sera from AOApositive patients showed reactivity only to the specific epitopes indicating that these regions of the proteins when exposed to the immune system led to an autoimmune condition. Also, peptide ELISA exhibited a superior platform in terms of sensitivity, specificity, and accuracy compared with the Rp in the previous study (Mande et al. 2011). Thus, the peptides constitute promising candidates for standardization of the serodiagnosis of human ovarian autoimmunity and could, therefore, be used as probable biomarkers for the diagnosis of such autoimmune pathologies.

The three proteins namely $\alpha$-ACTN4, HSPA5, and ACTB have been reported to play multiple functional roles in variety of cell types and systems and have been implicated in the pathogenesis of other autoimmune diseases. However, their role in ovarian function and specifically in ovarian autoimmunity has not been reported. A study by Zachos et al. (2008) describes the role of $\alpha$-ACTN4 in oocyte microvilli development. HSPA5 has been reported to be essential for embryo development and pluripotent cell survival (Luo et al. 2006). ACTB has also been reported to be required in oocyte development, fertilization, and wide range of important events during early embryogenesis like polar body extrusion, cytokinesis, chromosome segregation, and eventually egg production in Caenorhabditis elegans (Velarde et al. 2007). This raises the possibility of interference of antibodies to these three proteins in events leading to ovarian failure in humans. Therefore, studies demonstrating the effects of active immunization of female mice with antigenic epitopes of these target proteins will provide an insight into their role in ovarian pathogenesis. It has been proposed that due to conformational differences between the peptide and the native protein or due to the inability of individuals to recognize certain epitopes due to MHC restriction, individual peptides are often ineffective as immunogens compared with the native protein targets (Lou et al. 1995, Lea et al. 1998). Hence, immunizations with multiple antigenic epitopes can potentially more closely mimic natural autoimmunity, where the immune 
A a
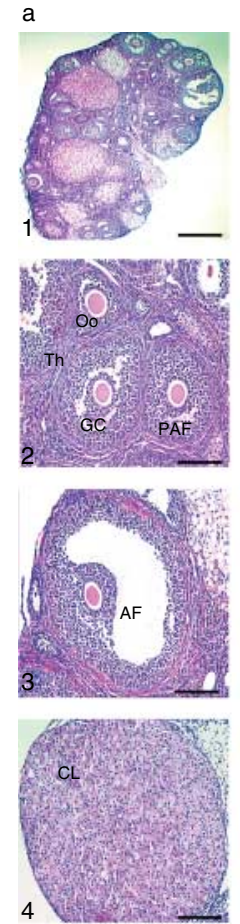

b
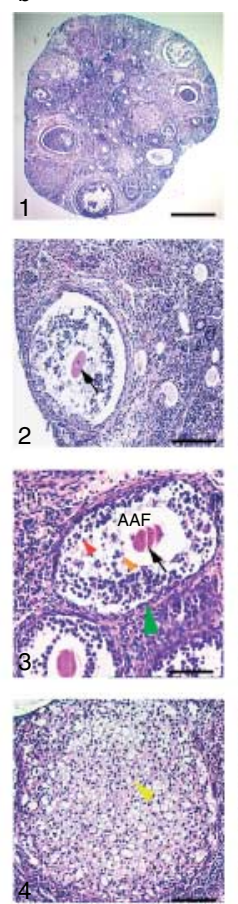

C
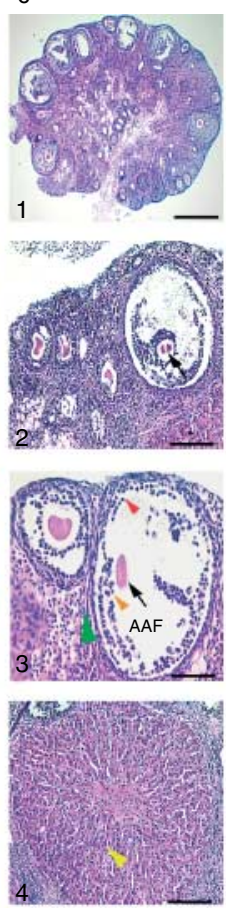

d
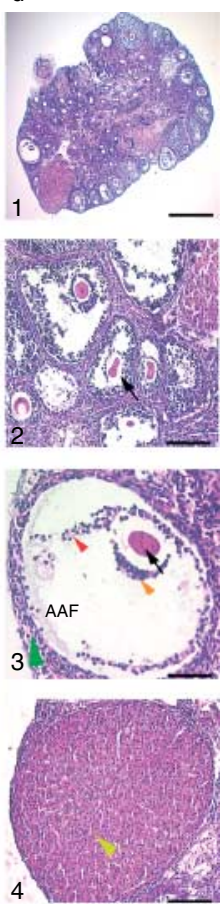

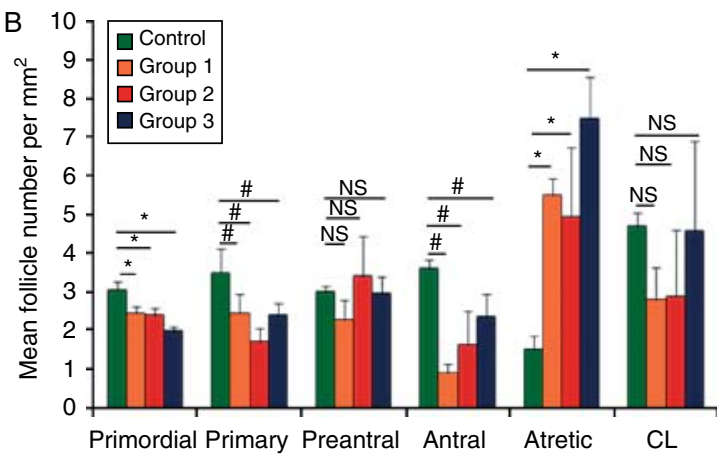

Type of follicles

Figure 4 (A) Transverse sections of ovaries (stained with hematoxylin and eosin) of mice showing histological changes following administration of different peptides of group 1 ( $\alpha$-ACTN4, panels b1-b4), group 2 (HSPA5, panels c1-c4), and group 3 (ACTB, panels d1-d4). Panels a1-a4 represent sections of ovaries of control mice immunized with PBS alone showing normal oocyte (Oo), corpus luteum (CL), theca (Th), granulosa (Gr), healthy preantral follicle (PAF), and antral follicle (AF). Ovaries of immunized mice showing deformed and pyknotic oocyte (black arrow), thinner theca (green arrowhead), thinner granulosa (red arrowhead), atretic antral follicles (AAF), and dissociated cumulus-oocyte complexes (orange arrowhead) and unhealthy corpus luteum (yellow arrowhead). Panels a1-d1, a2-d2, a3-d3, and a4-d4 represent scale bar $=2500,140,40$, and 40 $\mu \mathrm{m}$ respectively. (B) Histogram showing statistical analysis of mean number of follicles per square millimeter in group 1 ( $\alpha$-ACTN4, orange bar), group 2 (HSPA5, red bar), group 3 (ACTB, blue bar), and control animals (PBS alone, green bar) (five sections per ovary, four ovaries per group) represented as mean \pm S.E.M. *Significant differences in the mean number of follicles $(P<0.001) ;{ }^{\sharp} P<0.01 ; N S$, not significant, as analyzed by one-way ANOVA.

responses to different antigenic molecules lead to a physiological effect (Bach et al. 1998). In view of these reports, we pooled three dominant antigenic peptides (as obtained by peptide ELISA) of each antigen and immunized three groups of mice and studied its effect on various aspects of mouse ovarian development and functions. It was observed that the sera from all groups of mice exhibited high antibody titers against the pooled peptides and the antisera from respective groups reacted specifically to the native and Rp of each of these proteins and to different ovarian cell types such as oocyte, theca, and $\mathrm{CL}$ in the normal mouse ovarian sections. A strong reactivity to oocyte, theca, $\mathrm{CL}$, and granulosa was comparable to that seen using sera of women with POF and IVF-ET failures as well as the commercial antibodies as reported previously (Mande et al. 2011). This confirms the specificity of the autoantibodies to these target antigens.

Active immunization with dominant peptides of the three proteins caused a significant reduction in fertility in the immunized groups of mice. A robust immune response generated postimmunization was enough to cause an overall $25-43 \%$ reduction in fertility in the immunized mice compared with the control animals.
It was observed that the immunized female mice consistently showed longer diestrus compared with control mice, along with a delay in pregnancy and embryo resorptions in some of the animals, indicating a possible autoimmune mechanism. This could possibly explain high abortion rates in AOA-positive women recruited for IVF-ET program (Narayanan et al. 1995).

Histological findings indicate a deformed morphology of the ovary showing significant differences in the number of primordial follicles, primary follicles, PAF, and AFs between immunized and control mice, which possibly attribute to decrease in the number of quality oocytes and decrease in preimplantation embryos. The major defect was the arrest of follicular maturation at the antral stage and an increase in the number of atretic follicles in these ovaries. The transition of PAF to early AF is a critical stage in the follicular growth and is known to be regulated by oocyte-granulosa-theca cell interactions. Also, the preantral to antral transition is most susceptible to follicular atresia. Several oocyte- and theca cell-derived factors promote granulosa cell proliferation and suppress apoptosis of granulosa cells, thereby preventing follicular atresia (Parrott \& Skinner 2000, Orisaka et al. 2009). It has been demonstrated that 
a
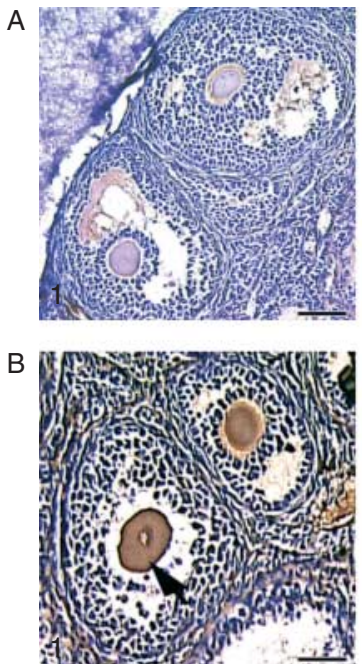

C

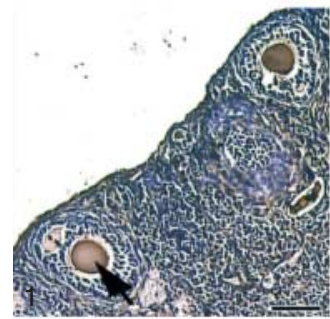

D

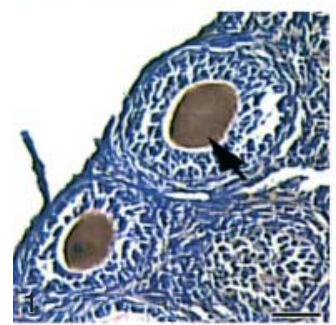

b
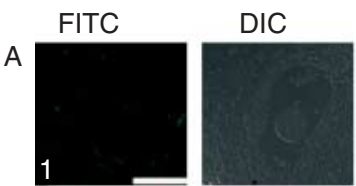

$\mathrm{B}$
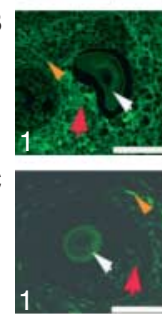

$\mathrm{D}$
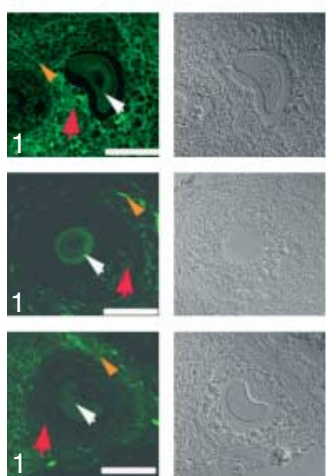
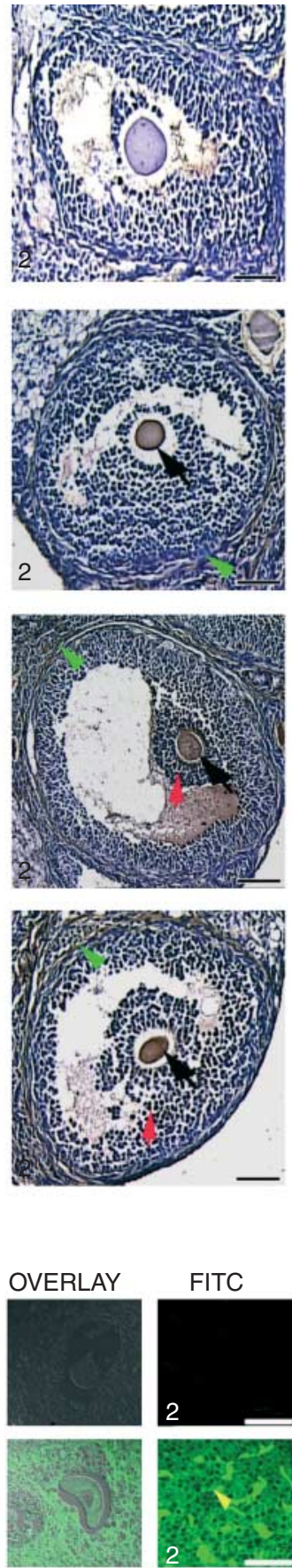
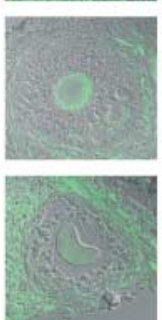
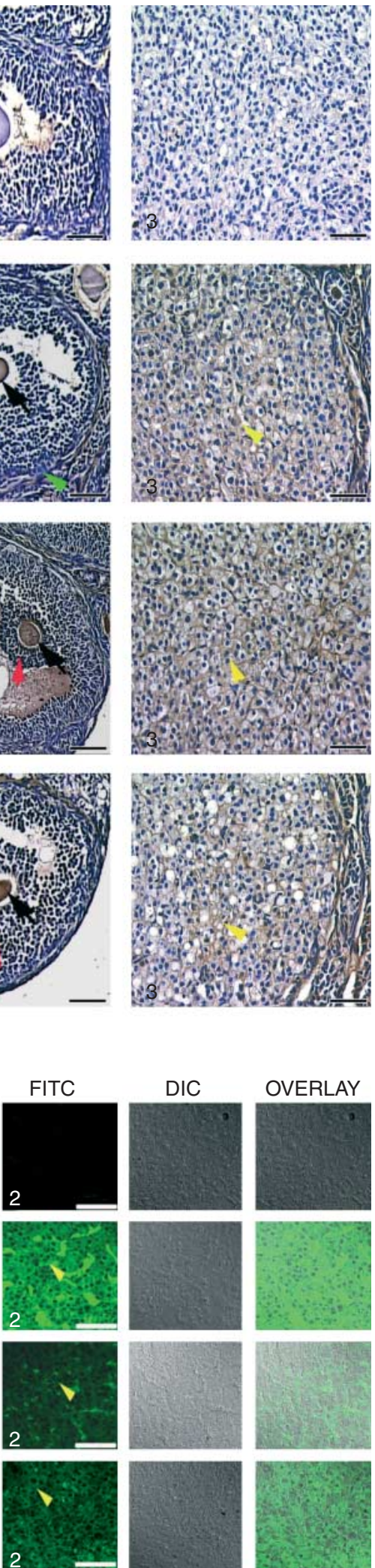
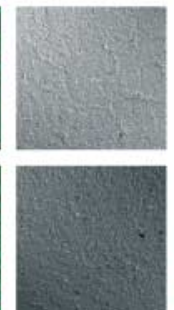

Figure 5 (a) Immunohistochemical localization of various target proteins in sections of normal mouse ovary on oocyte (black arrow), theca (green arrowhead), corpus luteum (yellow arrowhead), and granulosa (red arrow) using pooled sera from mice immunized with (A) PBS alone and different peptides of (B) group 1 ( $\alpha$-ACTN4), (C) group 2 (HSPA5), and (D) group 3 (ACTB) respectively. Scale bar represents $40 \mu \mathrm{m}$. (b) Direct immunofluorescence showing in vivo binding of the IgGs to the oocyte (panel 1, white arrow), theca (panel 1, orange arrowhead), granulosa (panel 1, red arrow), and corpus luteum (panel 2, yellow arrowhead) of (B) group $1(\alpha-A C T N 4)(C)$ group 2 (HSPA5), and (D) group 3 (ACTB) peptide-immunized mice. Ovaries from mice immunized with $(A)$ PBS alone did not show any IgG binding. Confocal images of IgG-specific signals (panels 1 and 2), DIC image (middle panels), and overlays of fluorescence with corresponding DIC images (right panels) are shown. Scale bar represents $20 \mu \mathrm{m}$. 
oocyte-theca cell interaction also has a major role in folliculogenesis including activation of resting follicles, early growth, as well as terminal differentiation (Vanderhyden et al. 1990, 1992, Eppig et al. 2002,

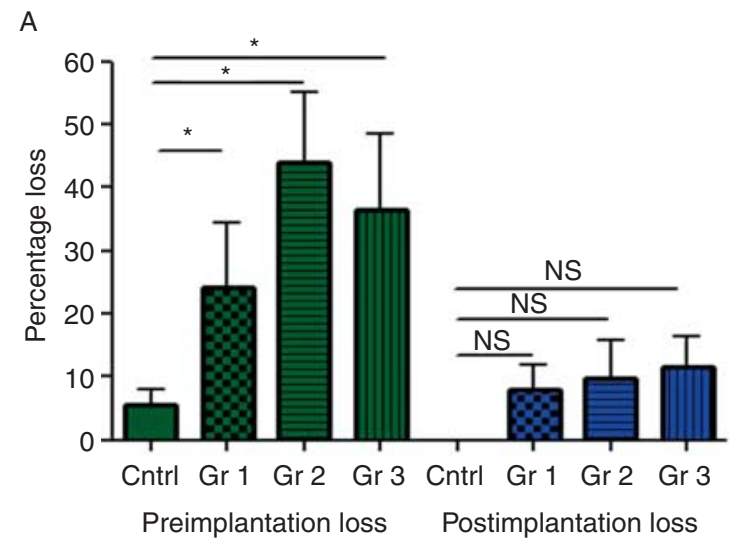

B

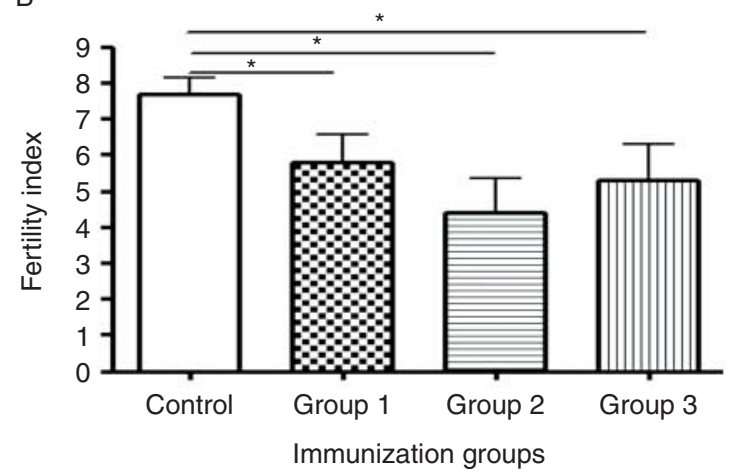

C

1

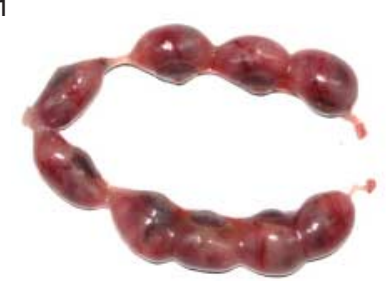

2

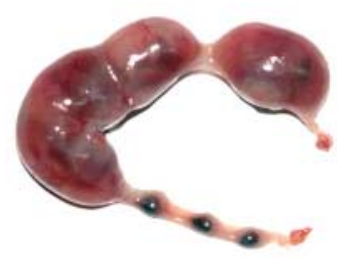

Figure 6 (A) Histogram representing the effect of immunization of peptides of group 1 ( $\boldsymbol{\alpha}$-ACTN4), group 2 (HSPA5), and group 3 (ACTB) on preimplantation (green bars) and postimplantation (blue bars) loss in peptide-immunized groups. Plain bar, checkered bar, horizontal line bar, and vertical line bar represent percentage losses in control, group 1 , group 2 , and group 3 animals respectively. ${ }^{*}$ Significant difference with respect to controls at $P<0.05$; NS, not significant. The values represent mean \pm S.E.M. ( $n=10$ females per group). Data were analyzed by paired $t$-test. (B) Fertility index following active immunization with PBS, group 1 ( $\alpha$-ACTN4), group 2 (HSPA5), and group 3 (ACTB) peptides are depicted by unfilled, checkered, horizontal line, and vertical line bars respectively. Fertility index is defined as the mean ( \pm S.E.M.) number of viable fetii per mated female. ${ }^{*} P<0.05$ between the peptide-immunized and control groups analyzed by one-way ANOVA. (C) Representative picture of 1) uterine complex from control animals displaying normal implantations and 2) uterus showing resorbed embryos in Balb/c mice immunized with different peptides of different targets on day 18 of pregnancy.
Matzuk et al. 2002). Further, granulosa cells also play a decisive role in the formation of theca cells by the secretion and action of soluble factors. These factors have been shown to be indispensable for theca cells to sustain their morphology and function (Kotsuji et al. 1990). Therefore, intactness essential for interaction of all these cellular layers is absolutely critical for normal folliculogenesis. However, following immunization, we observed that the granulosa and thecal cell layers were thinner in the ovaries of immunized groups compared with controls along with a deformed oocyte, indicating an effect of antibodies on the development of these cell types leading to a prominent apoptosis event being initiated in the follicles as evidenced by an increase in the number of atretic follicles. The presence of pyknotic oocytes in these ovaries constitutes the classic landmark of follicular atresia, indicating an autoimmune attack on the oocyte. Furthermore, cumulus cells were found to be more dissociated from the oocytes in immunized ovaries compared with control ovaries. The poor quality of oocytes and COCs thus implies a lower fertilization rate of oocytes resulting in diminished embryo development and reduced fertility of immunized mice as evidenced by the antifertility results. This raises the possibility of breakdown of the bidirectional communication between the oocyte-cumulus complex being targeted by the autoantibodies, leading to the degeneration of this complex and a loss of function ultimately leading to infertility. This was reflected by a significant increase in the preimplantation embryo loss in the peptide-immunized groups compared with the control group. This led us to speculate that antibodies elicited in the immunized mice could have induced functional defects in the oocyte leading to preimplantation embryo loss. The qualitative changes observed in the $\mathrm{CL}$ of the immunized groups compared with control group indicated the possible cause of the postimplantation loss observed in our study. It is known that $\mathrm{CL}$ is essential for establishing and maintaining pregnancy. Antibodies targeting the $\mathrm{CL}$ as reported earlier using patient's sera (Mande et al. 2011) might be affecting its normal function and ultimately a defective implantation leading to embryo loss in mice as observed in this study. Similar findings have been observed in studies showing an active immunization with recombinant zona pellucida (ZP3) or ZP3 chimeric peptides leading to deformed ovarian morphology with altered ovarian follicular differentiation and reduced fertility in mice and rabbits (Skinner et al. 1984, Lou et al. 1995, O'Leary et al. 2008). Thus, our findings of an increased incidence of preimplantation embryonic loss in successfully mated females and an increased incidence of postimplantation loss in pregnant females suggest that autoantibodies against these three proteins localized in different cellular compartments of the ovary other than ZP, like oocyte, theca, $\mathrm{CL}$, and granulosa adversely affects 
preimplantation embryos and also the later survival and growth of embryos.

In conclusion, this study highlights the relevance of three specific ovarian antigens $\alpha$-ACTN4, HSPA5, and ACTB in ovarian development and emphasizes their role as putative targets in autoimmune attack. The study may thus provide the basis to understand the pathophysiological mechanism underlying in cases like POI and IVF-ET failures in humans. The mouse model clearly reiterates precise importance of all cellular interactions being orchestrated in the ovary and gives us a glimpse as to how dysregulation in these interactions may lead to ovarian pathology leading to altered cyclicity, defective follicular maturation, pre- and postimplantation losses, and thereby reduced fertility. Determination of antibodies to the three targets is, therefore, highly recommended in evaluation of women with autoimmune POI and IVF-ET failures. The investigation further provides an additional basis for detecting the immunodominant epitopes of the three immunodominant ovarian autoantigens, getting rid of the cross-reactive epitopes, thereby leading to the possibility of development of a more specific and sensitive diagnostic test for the detection of autoantibodies in women with such autoimmune abnormalities and their subsequent prognosis. The data, therefore, provide us a strong platform for setting up a diagnostic tool and probably a therapeutic possibility to help a population of women whose ovarian function may be reinstated with appropriate therapy.

\section{Materials and Methods}

Protease inhibitor cocktail was obtained from Roche Diagnostics $(\mathrm{GmbH})$ and nonfat dry milk (NFDM) from Amul (Mumbai, India). Molecular weight marker, nitrocellulose membrane (NC), and ECL Plus Western Blotting Detection kit were obtained from GE Healthcare (Piscataway, NJ, USA), and secondary antibody from Sigma and Dako Cytomation (Glostrup, Denmark). ELISA plates were purchased from Nunc (Roskilde, Denmark). All other reagents were procured from Qualigens (Mumbai, India) and SRL India Ltd. (Mumbai, India) unless mentioned. Rp were obtained from Abnova, Taipei, Taiwan.

\section{Study population}

The study was approved by the clinical ethics committee of National Institute for Research in Reproductive Health. The inclusion and exclusion criteria for the selection of study participants is as described earlier (Mande et al. 2011). Briefly, women diagnosed with POI, infertile women recruited for IVFET program, and normally menstruating proven fertile women constituted the study groups. POI was diagnosed by clinicians as amenorrhea (lasting for 6 months) before the age of 40 years and high serum FSH levels ( $>40 \mathrm{IU} / \mathrm{ml}$ estimated twice 1 month apart). Women who have undergone pelvic surgery, radiation/ chemotherapy, genetic involvement, abnormal karyotypes, or viral oophoritis were excluded from the study. For IVF-ET group, infertile women who were $<40$ years of age and enrolled for IVF-ET program and had normal pelvic ultrasound examination and normal uterine cavity were included in the study. While women who had uterine/ovarian surgery, pelvic inflammatory disease, endometriosis, polycystic ovarian syndrome, and fibroids were excluded from the study, women with any other autoimmune disease were excluded from both study groups.

AOA-positive sera of women recruited for IVF-ET and women with POI $(n=137 ; \alpha$-ACTN4 targeting sera $=43$, HSPA5 targeting sera $=64$, and ACTB targeting sera $=30$ ) and AOAnegative sera from age-matched, healthy, regularly menstruating proven fertile women serving as controls $(n=35)$ were used for the peptide ELISA experiments.

\section{Peptide design}

The epitopes for the three previously identified proteins namely $\alpha$-ACTN4, HSPA5, and ACTB were determined using the antigenicity prediction methods such as Kolaskar \& Tongaonkar's method (Kolaskar \& Tongaonkar 1990), Bepipred Linear Epitope Prediction (Larsen et al. 2006), and DISCOTOPE (Haste et al. 2006). The antigenic regions predicted by these methods were compared and the regions commonly identified by these algorithms were short-listed. These regions were then checked for sequence similarities with other known proteins using the online BLASTP tool available at NCBI (Altschul et al. 1997). Sequences that were predicted to be antigenic and did not share substantial sequence identity with other proteins were considered for peptide synthesis and subsequent ELISA for each of these proteins.

\section{Peptide synthesis}

Ten peptides each of $\alpha$-ACTN4 and ACTB (designated as P1P10) and seven peptides of HSPA5 (designated as P1-P7) were chemically synthesized by solid-phase synthesis using Fmoc chemistry (Table 1). The purity of each peptide was above $90 \%$ as determined using HPLC. All peptides for immunization were conjugated to the carrier protein Keyhole Limpet Hemocyanin $(\mathrm{KLH})$. Synthesis and conjugation of the peptides was done by US Vitamins Ltd., Mumbai, India.

\section{Peptide ELISA}

Flat bottom 96-well microtiter plates were coated with $1 \mu \mathrm{g}$ each of unconjugated peptide of all three proteins individually namely $\alpha$-ACTN4, ACTB, and HSPA5 in $50 \mu$ l coating buffer (carbonate-bicarbonate buffer, $\mathrm{pH} 9.2$ ) per well at $4{ }^{\circ} \mathrm{C}$ in a humidified chamber overnight. Excess antigen was removed and wells were blocked with $2 \%$ porcine gelatin (Sigma) in $0.01 \mathrm{M}$ PBS for $2 \mathrm{~h}$ at $37^{\circ} \mathrm{C}$. Neat patients' sera targeting respective ovarian antigens were added to the wells and incubated overnight at $4{ }^{\circ} \mathrm{C}$. After washings with $0.05 \%$ Tween 20-PBS (v/v), $50 \mu \mathrm{l} /$ well of HRP-conjugated goat antihuman IgG secondary antibody (Sigma) was added (1:2000 dilution) and incubated for $1 \mathrm{~h}$ at $37^{\circ} \mathrm{C}$, followed by addition of $100 \mu \mathrm{l} /$ well of $3,3^{\prime}, 5,5^{\prime}$-tetramethylbenzidine $+\mathrm{H}_{2} \mathrm{O}_{2}$ substrate (Genei, Bangalore, India). The reaction was terminated after $5 \mathrm{~min}$ with $50 \mu \mathrm{l} /$ well of $2 \mathrm{M} \mathrm{H}_{2} \mathrm{SO}_{4}$ solution and the 
absorbance was measured at $450 \mathrm{~nm}$ using Universal Micro plate Reader (Bio-Tek Instruments, Inc., Winooski, VT, USA). An URP (NDUFA9 protein, sequence LLFHLVKYIRWFLAVPLVSLGF) was used to ensure the specificity of the reactivity of patients' sera with the target peptides. Ten representative sera from each group were used against the URP. The individual patient sample was considered positive if the absorbance was mean +2 s.D. higher than the control sample.

\section{Animals}

Pathogen-free Balb/c female and male mice (6 weeks old, $25 \mathrm{~g}$ in weight) were maintained with food and water ad libitum in a temperature- and humidity-controlled room with a $12 \mathrm{~h}$ light:12 h darkness cycle. All the experimental protocols were approved by the Institutional Ethics Committee for Care and Use of Laboratory Animals for Biomedical Research.

\section{Immunization schedule}

The sexually mature female Balb/c mice were bled retroorbitally for preimmune bleeds and then randomized into four groups of 14 mice each as shown in Table 3. Each group was immunized subcutaneously with three of the immunodominant peptides of each of the three proteins obtained from peptide ELISA studies (Table 2). All injections employed the same dose of $100 \mu \mathrm{g}$ each of the KLH-conjugated immunogen (peptide) diluted in $0.01 \mathrm{M}$ PBS $(\mathrm{pH}=7.2)$ and emulsified with an equal volume of Complete Freund's Adjuvant (Sigma) for first injection and at 2-week intervals in Freund's Incomplete Adjuvant (Sigma) for two subsequent booster injections. The control mice were immunized with adjuvant containing PBS or $\mathrm{KLH}$ (Pierce, Rockford, IL, USA) alone. Blood was collected at 2, 4, and 6 weeks after first day of injection. The serum was separated and stored at $-20{ }^{\circ} \mathrm{C}$ until tested. Ovaries for histopathological analysis and immunohistochemical staining were collected from each female mouse per group at 6 weeks $(n=4)$.

\section{Antipeptide antibody response}

The antibodies against $\alpha$-ACTN4, HSPA5, and ACTB peptides in the sera of immunized mice were assayed by ELISA in 96-well microtiter plates. The plates were coated with pooled peptides of each group ( $1 \mu \mathrm{g}$ each in $50 \mu$ l coating buffer, $\mathrm{pH}=9.2$, per well) and incubated at $4{ }^{\circ} \mathrm{C}$ in a humidified chamber overnight. The assay was performed as described above. Preimmune (pre) as well as postimmune sera (P1, 2 weeks; P2, 4 weeks; and P3, 6 weeks after immunization and day 18 of pregnancy) from control and immunized animals diluted 1:10 served as the primary antibody. HRP-conjugated rabbit antimouse IgG antibody (1:1000, Dako Cytomation) served as the secondary antibody. Buffer alone served as negative control. The mean \pm S.E.M. of antibody titers was calculated for each group.

\section{Western blotting}

To validate the ability of antipeptide antibodies in immunized mice sera to detect the native proteins namely $\alpha$-ACTN4,
ACTB, and HSPA5, SDS-PAGE western blot analysis was performed as described earlier (Mande et al. 2011). Briefly, mouse whole ovarian lysate $(40 \mu \mathrm{g})$ and the $\mathrm{Rp}$ (500 ng each) were run on a $10 \%$ SDS-PAGE and the resolved proteins were transferred on NC membrane for $1 \mathrm{~h} 15 \mathrm{~min}$ at $23 \mathrm{~V}$. The individual lanes were cut and blocked with $5 \%$ NFDM for $1 \mathrm{~h}$ at room temperature (RT). The strips were probed overnight at $4{ }^{\circ} \mathrm{C}$ with $1: 10$ diluted postimmune mice sera from respective groups. The membranes were washed with $0.1 \%$ PBS-Tween-20 thrice and incubated with HRP-conjugated rabbit antimouse IgG secondary antibody diluted at 1:3500 in 1\% blocking buffer for $1 \mathrm{~h}$ at RT followed by washings as above and chemiluminescent detection of proteins using ECL plus detection kit. Three sets of negative controls were used, one set was buffer control or secondary alone control where PBS was added in place of primary antibody. For the second set of negative control, 1:10 diluted preimmune mice sera from respective groups were used. For the third set, 1:10 diluted postimmune sera from control mice were used.

\section{Histopathological analysis}

Ovaries from immunized and control mice were dissected at 6 weeks after immunization, fixed for $48 \mathrm{~h}$ in $4 \%$ paraformaldehyde (Sigma), paraffin-embedded, and sectioned with each section of $5 \mu \mathrm{m}$ thickness. A total of 50 intact sections (two sections per slide) were obtained. Sections from every fifth slide were processed for histopathology. Briefly, sections were deparaffinized at $56{ }^{\circ} \mathrm{C}$ in xylene and rehydrated in decreasing alcohol grades (100-30\%). The sections were then stained with $0.2 \%$ hematoxylin and $1 \%$ eosin, dehydrated in increasing alcohol grades (30-100\%), and mounted with DPX mountant for light microscopic observation under DMLA Laser Capture Microdissection microscope (Leica, Wetzler, Germany) at magnifications $4 \times, 20 \times$, and $40 \times$. The number of follicles in one representative section per slide of each ovary (five sections per ovary and four ovaries per group) was counted along the $X$ - and $Y$-axes from top to bottom of the section using the grid system in ADOBE Photoshop version 7 (Adobe Systems). Oocytes of follicles falling within the grids were scored, while oocytes intersected by the grid boundary were excluded to avoid multiple scoring. The number of follicles for each ovary was normalized by the total area of the ovary in the section. The area of the ovary was measured with PHOTO$\mathrm{SHOP}$ version 7.0. Follicle types in ovarian cross sections were classified as reported earlier (Britt et al. 2000, Cheng et al. 2002). Briefly, primordial follicles were defined as an oocyte surrounded by a single layer of squamous (flattened) granulosa cells. Primary follicles were classified as oocyte surrounded by single layer of cuboidal granulosa cells. Follicles with more than one layer of granulosa cells and no visible antrum were classified as PAFs, while AFs contained a large antral space and a distinct oocyte surrounded by cumulus cells. Atretic follicles were characterized by two or more pyknotic nuclei, granulosa cells within the antral cavity, granulosa cells pulling away from the basement membrane, or uneven layers of granulosa cells. 


\section{Immunohistochemistry and direct immunofluorescence}

Reactivity of anti- $\alpha$-ACTN4, anti-ACTB, and anti-HSPA5 antibodies to various ovarian cell types was detected by immunohistochemistry as described earlier (Mande et al. 2011). Ovaries from normal mouse were fixed in $4 \%$ paraformaldehyde for $24 \mathrm{~h}$ and paraffin embedded. Sections $(5 \mu \mathrm{m})$ were deparaffinized in xylene and processed through decreasing alcohol grades and rinsed in $0.01 \mathrm{M}$ PBS. The sections were then blocked with 5\% NFDM for $1 \mathrm{~h}$ at RT in a humid chamber. The sections were incubated with postimmune serum or PBS control serum diluted 1:5 in 0.01 M PBS or 0.01 M PBS alone overnight at $4{ }^{\circ} \mathrm{C}$. Antibody bound to various cellular targets was detected by HRP-conjugated rabbit antimouse IgG (1:100). The reactivity was detected using 3,3'-diaminobenzidine (DAB) substrate chromogen solution (Sigma), counterstained for 30 s using Delafield's hematoxylin, dehydrated through series of alcohol grades, cleared in xylene, and mounted in DPX mounting medium. Slides were examined on DMLA Laser Capture Microdissection microscope (Leica) at a magnification of $40 \times$. Preimmune sera and buffer alone served as negative controls.

In vivo binding of antibodies to the three proteins was detected by direct immunofluorescence. Mouse ovarian sections (5 $\mu \mathrm{m}$ thickness) from peptide-immunized animals or PBS controls were processed as described above. The sections were blocked with $3 \%$ BSA for $1 \mathrm{~h}$ in a humid chamber at RT. After rinsing with PBS, the bound antibody was detected by FITC-conjugated rabbit antimouse IgG (1:100) for $1 \mathrm{~h}$. The slides were rinsed and mounted in Vectashield medium (Vector Laboratories, Burlingame, CA, USA). Images were acquired under confocal microscope (Carl Zeiss LSM-510-META, Jena, Germany) at a magnification of $40 \times$ and wavelength $488 \mathrm{~nm}$ for green (Argon Laser, Jena, Germany) for $\alpha$-ACTN4, HSPA5, and ACTB.

\section{Fertility studies}

About 2 weeks after the final immunization, ten female mice from each immunized group were continuously mated with 8- to 10-week-old proven fertile male Balb/c mice (two females:one male per cage) to check the effect of antipeptide antibodies on mating parameters and reproductive outcome. The mice were monitored every morning for vaginal plugs and cyclicity. At day 18 of gestation, the mice from each group were killed and uterus was exposed to reveal the number of live, dead, and resorbed fetii in their uterus. The number of implantation sites was recorded. The ovaries were isolated and the number of CL was determined by visual inspection. Data were analyzed to determine pre- and postimplantation loss as given below (Balasinor et al. 2002):

Preimplantation loss (\%)

$$
=\frac{\text { No. of corpora lutea }- \text { No. of implantation sites }}{\text { No. of corpora lutea }} \times 100 \text {. }
$$

Postimplantation loss (\%)

$$
=\frac{\text { No. of implantation sites }- \text { No. of live fetus }}{\text { No. of implantation sites }} \times 100
$$

The results were presented as mean \pm s.E.M. Fertility index was defined as the mean number ( \pm S.E.M.) of viable fetii per mated female. Serum antibody titers at day 18 of pregnancy were examined using ELISA method as described earlier.

\section{Statistical analysis}

Peptide ELISA results (using patient's sera) recorded as absorbance at $450 \mathrm{~nm}$ were distributed by using a scatter plot. The cutoff values for positivity toward a peptide were determined as the mean OD of the control samples plus two S.D. of that mean. Comparison and degrees of significance were assessed by Mann-Whitney unpaired $t$-test. The sensitivity was calculated as (True positive/True positive + False negative) $X$ 100, specificity as (True negative/True negative + False positive) $\times 100$, and accuracy as (True positive + True negative/True positive + False negative + True negative + False positive) $\times 100$. Antipeptide antibody titers in mice sera determined using ELISA were assessed by unpaired t-test. Histological data and diestrus length are presented as mean \pm s.E.M. and analyzed using one-way ANOVA. The mean number of viable fetii, implantation sites, and CL among the pregnant female mice in a group is presented as mean \pm s.E.M. Pre- and postimplantation losses were analyzed by paired $t$-test. Fertility index was analyzed by one-way ANOVA. Differences were considered significant at $P<0.05$ after one-way ANOVA followed by Dunnett's multiple comparison post hoc test. Statistical analysis was performed using GraphPad Prism software version 4 (GraphPad Software, San Diego, CA, USA).

\section{Declaration of interest}

The authors declare that there is no conflict of interest that could be perceived as prejudicing the impartiality of the research reported.

\section{Funding}

This work was supported by grants from the Department of Biotechnology, Delhi, Government of India (grant no: BT/IN/US/CRHR/14/VK/2007) and by intramural funding from National Institute for Research in Reproductive Health (ICMR), Delhi, Government of India.

\section{Acknowledgements}

The authors sincerely thank Dr Ikram Khatkhatey from National Institute for Research in Reproductive Health for statistical assistance and Dr Firuza Parikh, Dr Indira Hinduja, Dr Kusum Zaveri, Dr Rama Vaidya, and Dr Rahul Gajbhiye for providing blood samples of IVF-ET recruits and women with POI. Technical support of Ms Mamta Gurav, Mr Manish Ghosalkar, Mr M Merchande, and Mr D Gaikwad, and staff from central confocal facility of National Institute for Research in Reproductive Health is gratefully acknowledged. Financial support to Ms Purvi Mande is gratefully acknowledged from the Department of Biotechnology and Indian Council of Medical Research, Government of India. 


\section{References}

Alix AJ 1999 Predictive estimation of protein linear epitopes by using the program PEOPLE. Vaccine 18 311-314. (doi:10.1016/S0264-410X (99)00329-1)

Altschul SF, Madden TL, Schäffer AA, Zhang J, Zhang Z, Miller W \& Lipman DJ 1997 Gapped BLAST and PSI-BLAST: a new generation of protein database search programs. Nucleic Acids Research 25 3389-3402. (doi:10.1093/nar/25.17.3389)

Bach JF, Koutouzov S \& van Endert PM 1998 Are there unique autoantigens triggering autoimmune diseases? Immunological Reviews 164 139-155. (doi:10.1111/j.1600-065X.1998.tb01216.x)

Balasinor N, Gill-Sharma MK, Parte P, D'Souza S, Kedia N \& Juneja HS 2002 Effect of paternal administration of an antiestrogen, tamoxifen on embryo development in rats. Molecular and Cellular Endocrinology 190 159-166. (doi:10.1016/S0303-7207(01)00723-7)

Bodman Smith MD, Corrigall VM, Berglin E, Cornell HR, Tzioufas AG, Mavragani CP, Chan C, Rantapää-Dahlqvist S \& Panayi GS 2004 Antibody response to the human stress protein $\mathrm{BiP}$ in rheumatoid arthritis. Rheumatology 43 1283-1287. (doi:10.1093/rheumatology/ keh312)

Boulassel MR, Tomasi JP, Deggouj N \& Gersdorff M 2001 Identification of $\beta$-actin as a candidate autoantigen in autoimmune inner ear disease. Clinical Otolaryngology and Allied Sciences 25 535-541.

Britt KL, Drummod AE, Cox VA, Dyson M, Wreford NG, Jones MEE, Simpson ER \& Findlay JK 2000 An age related ovarian phenotype in mice with targeted disruption of the cyp19 (aromatase) gene. Endocrinology 141 2614-2623. (doi:10.1210/en.141.7.2614)

Cheng G, Weihua Z, Makinen S, Makela S, Saji S, Warner M, Gustaffson JA \& Hovatta O 2002 A role for the androgen receptor in follicular atresia of estrogen receptor beta knockout mouse ovary. Biology of Reproduction 66 77-84. (doi:10.1095/biolreprod66.1.77)

Coulam CB, Adamson SC \& Annegers JF 1986 Incidence of premature ovarian failure. Obstetrics and Gynecology 67 604-606.

Damewood MD, Zacur HA, Hoffman GJ \& Rock JA 1986 Circulating antiovarian antibodies in premature ovarian failure. Obstetrics and Gynecology 68 850-854.

Edassery SL, Shatavi SV, Kunkel JP, Hauer C, Brucker C, Penumatsa K, Yu Y, Dias JA \& Luborsky JL 2010 Autoantigens in ovarian autoimmunity associated with unexplained infertility and premature ovarian failure. Fertility and Sterility 94 2636-2641. (doi:10.1016/j.fertnstert.2010. 04.012)

Elkon KB 1992 Use of synthetic peptides for the detection and quantification of autoantibodies. Molecular Biology Reports 16 207-212. (doi:10.1007/BF00464709)

Eppig JJ, Wigglesworth K \& Pendola FL 2002 The mammalian oocyte orchestrates the rate of ovarian follicular development. PNAS 99 2890-2894. (doi:10.1073/pnas.052658699)

Forges T, Monnier-Barbarino P, Faure GC \& Béné MC 2004 Autoimmunity and antigenic targets in ovarian pathology. Human Reproduction Update 10 163-175. (doi:10.1093/humupd/dmh014)

Gobert B, Jolivet-Reynaud C, Dalbon P, Barbarino-Monnier P, Faure GC \& Jolivet M 2001 An immunoreactive peptide of the FSH involved in autoimmune infertility. Biochemical and Biophysical Research Communications 289 819-824. (doi:10.1006/bbrc.2001.6059)

Gueguen P, Dalekos G, Nousbaum JB, Zachou K, Putterman C, Youinou P \& Renaudineau Y 2006 Double reactivity against actin and alpha-actinin defines a severe form of autoimmune hepatitis type 1. Journal of Clinical Immunology 26 495-505. (doi:10.1007/s10875-006-9045-z)

Hardy CM, Clydesdale G \& Mobbs KJ 2004 Development of mouse specific contraceptive vaccines: infertility in mice immunized with peptide and polypeptide antigens. Reproduction 128 395-407. (doi:10.1530/rep.1. 00276)

Haste Andersen P, Nielsen M \& Lund O 2006 Prediction of residues in discontinuous B-cell epitopes using protein 3D structures. Protein Science 15 2558-2567. (doi:10.1110/ps.062405906)

Hoek A, Schoemaker J \& Drexhage A 1997 Premature ovarian failure and ovarian autoimmunity. Endocrinology Reviews 18 107-134. (doi:10. 1210/er.18.1.107)

Hopp TP \& Woods KR 1981 Prediction of protein antigenic determinants from amino acid sequences. PNAS 78 3824-3828. (doi:10.1073/pnas. 78.6.3824)
Kimura A, Sakurai T, Tanaka Y, Hozumi I, Takahashi K, Takemura M, Saito K, Seishima M \& Inuzuka T 2008 Proteomic analysis of autoantibodies in neuropsychiatric systemic lupus erythematosus patient with white matter hyperintensities on brain MRI. Lupus 17 16-20. (doi:10.1177/0961203307085112)

Kolaskar AS \& Tongaonkar PC 1990 A semi-empirical method for prediction of antigenic determinants on protein antigens. FEBS Letters 276 172-174. (doi:10.1016/0014-5793(90)80535-Q)

Kotsuji F, Kamitani N, Goto K \& Tominaga T 1990 Bovine theca and granulosa cell interactions modulate their growth, morphology and function. Biology of Reproduction 43 726-732. (doi:10.1095/biolreprod43.5.726)

Larsen JE, Lund O \& Nielsen M 2006 Improved method for predicting linear B-cell epitopes. Immunome Research 2 2. (doi:10.1186/1745-7580-2-2)

Lea IA, van Lierop MJ, Widgren EE, Grootenhuis A, Wen Y, van Duin M \& O'Rand MG 1998 A chimeric sperm peptide induces antibodies and strain specific reversible infertility in mice. Biology of Reproduction $\mathbf{5 9}$ 527-536. (doi:10.1095/biolreprod59.3.527)

Lou Y, Ang J, Thai H, McElveen F \& Tung KS 1995 A zona pellucida 3 peptide vaccine induces antibodies and reversible infertility without ovarian pathology. Journal of Immunology 155 2715-2720.

Luborsky J 2002 Ovarian autoimmune disease and ovarian autoantibodies. Journal of Women's Health Gender-Based Medicine 11 585-599. (doi:10.1089/152460902760360540)

Luo S, Mao C, Lee B \& Lee A 2006 GRP78/BiP is required for cell proliferation and protecting the inner cell mass from apoptosis during early mouse embryonic development. Molecular and Cellular Biology 26 5688-5697. (doi:10.1128/MCB.00779-06)

Mande P, Parikh FR, Hinduja I, Zaveri K, Vaidya R, Gajbhiye R \& Khole VV 2011 Identification and validation of candidate biomarkers involved in human ovarian autoimminity. Reproductive Biomedicine Online 23 471-483. (doi:10.1016/j.rbmo.2011.06.013)

Matzuk MM, Burns KH, Viveiros MM \& Eppig J 2002 Intercellular communication in the mammalian ovary: oocytes carry the conversation. Science 296 2178-2180. (doi:10.1126/science.1071965)

McClure JE \& Shearer WT 1988 Radioimmunoassay for anti-actin antibody: application in viral and autoimmune diseases. Molecular and Cellular Probes 2 305-319. (doi:10.1016/0890-8508(88)90014-X)

Mederois LR, Rosa DD, da Rosa MI \& Bozetti MC 2009 Accuracy of CA125 in the diagnosis of ovarian tumors: a quantitative systemic review. European Journal of Obstetrics, Gynecology, and Reproductive Biology 142 99-105. (doi:10.1016/j.ejogrb.2008.08.011)

Narayanan M, Murthy PSR, Munaf A, Shah LCP \& Kini MD 1995 Antiovarian antibodies and their effect on the outcome of assisted reproduction. Journal of Assisted Reproduction and Genetics 12 599-605. (doi:10.1007/BF02212582)

O'Leary S, Lloyd ML, Shellam GR \& Robertson SA 2008 Immunization with recombinant murine cytomegalovirus expressing murine zona pellucida 3 causes permanent infertility in BALB/C mice due to follicle depletion and ovulation failure. Biology of Reproduction 79 849-860. (doi:10. 1095/biolreprod.108.067884)

Orisaka M, Tajima K, Tsang BK \& Kotsuji F 2009 Oocyte-granulosa-theca cell interactions during preantral follicular development. Journal of Ovarian Research 2 9. (doi:10.1186/1757-2215-2-9)

Otsuka N, Tong Z-B, Vanevski K, Tu W, Cheng MH \& Nelson LM 2011 Autoimmune oophoritis with multiple molecular targets mitigated by transgenic expression of mater. Endocrinology 152 2465-2473. (doi:10. 1210/en.2011-0022)

Parker JM, Guo D \& Hodges RS 1986 New hydrophilicity scale derived from high-performance liquid chromatography peptide retention data: correlation of predicted surface residues with antigenicity and X-ray derived accessible sites. Biochemistry 25 5425-5432. (doi:10.1021/ bi00367a013)

Parrott JA \& Skinner MK 2000 Kit ligand actions on ovarian stromal cells: effects on theca cell recruitment and steroid production. Molecular Reproduction and Development 55 55-64. (doi:10.1002/(SICI)10982795(200001)55:1 < 55::AID-MRD8> 3.0.CO;2-L)

Pires ES \& Khole VV 2009 A block in the road to fertility: autoantibodies to heat shock protein $90 \beta$ in human ovarian autoimmunity. Fertility and Sterility 92 1395-1409. (doi:10.1016/j.fertnstert.2008.08.068)

Purcell AW, Todd A, Kinoshita G, Lynch TA, Kleech CL, Gething MJ \& Gordon TP 2003 Association of stress proteins with autoantigens: 
a possible mechanism for triggering autoimmunity? Clinical and Experimental Immunology 132 193-200. (doi:10.1046/j.1365-2249. 2003.02153.x)

Skinner SM, Mills T, Kirchick HJ \& Dunbar BS 1984 Immunization with zona pellucida proteins results in abnormal ovarian follicular differentiation and inhibition of gonadotropin-induced steroid secretion. Endocrinology 115 2418-2432. (doi:10.1210/endo-115-6-2418)

Sundblad V, Bussmann L, Chiauzzi VA, Pancholi V \& Charreau EH 2006 $\alpha$-Enolase: a novel autoantigen in patients with premature ovarian failure. Clinical Endocrinology 65 745-751. (doi:10.1111/j.1365-2265. 2006.02661.x)

Vanderhyden BC, Caron PJ, Buccione R \& Eppig JJ 1990 Developmental pattern of the secretion of cumulus expansion-enabling factor by mouse oocytes and the role of oocytes in promoting granulosa cell differentiation. Developmental Biology 140 307-317. (doi:10.1016/00121606(90)90081-S)

Vanderhyden BC, Telfer EE \& Eppig JJ 1992 Mouse oocytes promote proliferation of granulosa cells from prenatral and antral follicles in vitro. Biology of Reproduction 46 1196-1204. (doi:10.1095/ biolreprod46.6.1196)
Velarde N, Gunsalus K \& Fabio P 2007 Diverse roles of actin in C. elegans early embryogenesis. BMC Developmental Biology 7 142. (doi:10.1186/ 1471-213X-7-142)

Winqvist O, Gustafsson J, Rorsman F, Karlsson FA \& Kampe O 1993 Two different P450 enzymes are the adrenal antigens in autoimmune polyendocrine syndrome type I and Addison's disease. Journal of Clinical Investigation 92 2377-2385. (doi:10.1172/JCl116843)

Zachos NC, Burch MG, Billiar RB, Li C, Albrecht ED \& Pepe GJ 2008 Regulation of expression of microvillus membrane proteins by estrogen in baboon fetal ovarian oocytes. Biology of Reproduction 79 1160-1168. (doi:10.1095/biolreprod.108.067900)

Received 22 June 2011

First decision 1 August 2011

Revised manuscript received 31 October 2011

Accepted 1 December 2011 